\title{
Design and Implementation Of Blended Learning Approach For Simulation Education Among Undergraduate Nursing Students
}

\author{
Miran Eom', Sun Kyung Kim*2, Oe-Nam Kim ${ }^{3}$ \\ 1 Professor, Department of Nursing, Mokpo National University, 1666 Yeongsan-ro, Cheonggye-myeon, \\ Muan-gun, Jeollanam-do, 58554 \\ 2 Assistant professor, Department of Nursing, and Department of Biomedicine, Health \& Life Convergence \\ Science, BK21 Four, Mokpo National University, 1666 Yeongsan-ro, Cheonggye-myeon, Muan-gun, \\ Jeollanam-do, 58554 \\ ${ }^{3}$ Assistant professor, Department of Nursing, YoungNam Foreign Language College, 220-1 Hyeopseok-ri, \\ Namcheon-myeon, Gyeongsan, Korea
}

\begin{abstract}
Article History:Received:11 november 2020; Accepted: 27 December 2020; Published online: 05 April 2021
Abstract: The importance of undergraduate nursing education has never been higher due to the aging population and complexity of patients. The blended simulation combined two and more educational methods and is an effective strategy in nursing education. This study was to evaluate the effectiveness of blended simulation using standardized patients and patients simulation. Using a convenience sampling, a quasi-experimental study was conducted. Forty undergraduate nursing students enrolled and were allocated into the experimental group $(n=20)$ or the control group $(n=20)$. CPX (clinical performance examination) was used to evaluate physical assessment skills. Self-reporting questionnaires were used for communication skill and learning satisfaction. $\chi 2$-test/Fisher's exact test and Mann-Whitney $\mathrm{U}$ test were conducted for statistical analysis. After completing the educational program, there were statistically significant higher levels of physical assessment and communication skills in the blended simulation group $(\mathrm{p}<.001)$ compared with the control group. Regarding learning satisfaction, there were also statistically significant differences with higher level of satisfaction among students in blended simulation group ( $\mathrm{p}=.002$ ). This blended simulation has high potential to successfully achieve learning outcomes in undergraduate nursing education. Providing students diverse educational methods ensures an optimal learning experience.
\end{abstract}

Keywords: Standardized patient, Simulation, Nursing students, Communication, Satisfaction.

\section{INTRODUCTION}

Due to the dramatic growth in population aging, patients' acuity and complexity has never been higher such that physical assessment is recognized as a core nursing skill to ensure patient safety and quality nursing care in nursing education (Buist \& Stevens, 2013). Hospitalized patients, in particular, are admitted for more complicated treatment, which requires intensive nursing care and monitoring for changed physical status. Nurses as front-line staff are responsible for detecting individual patient problems in a timely manner. A patient's physical assessment is an important daily task that requires adequate training during undergraduate nursing curriculum.

In most nursing school curriculum, nursing students complete the program within a compressed timeframe, which challenges undergraduate nursing education (Posey \& Pintz, 2017). Faculties must formulate optimal teaching strategies to equip students with sound theoretical knowledge as well as adequate skills for future clinical practice. Moreover, integration of theoretical knowledge into real-life clinical situation is a key to successful nursing education. Thus, undergraduate nursing education must offer various experiences, facilitating students' readiness before entering the clinical field as a registered nurse.

Simulation-based learning has been recognized as an effective teaching strategy in undergraduate nursing education. The strategy includes various activities with diverse devices such as high-fidelity simulators (HFS), standardized patients (SPs), role play, and simple patient mannequins (Barry Issenberg et al., 2005). Welldeveloped scenarios based on clinical situations establish learning environment for nursing students where they are given opportunity to practice diverse skills, clinical and non-clinical skills, from communication to intricate nursing skills. This simulation-based learning has been applied to nursing education such that its effectiveness is well established in achieving high levels of nursing competency.

Technology development affects nursing education in that tertiary nursing education, especially simulation, adapts new technologies. Blended simulation is defined as a teaching strategy that involves integrating modern technology in teaching nursing practices (Johnson et al., 2010). Combining conventional face-to-face interventions with technological methods offers higher potential for educators to cater to diverse student learning preferences (Chan et al., 2010). As a matter of fact, previous studies reported higher levels of motivation occur through blended learning than from traditional, teacher-centered, passive educational

*Corresponding author: Sun Kyung Kim

Assistant professor, Department of Nursing, and Department of Biomedicine, Health \& Life Convergence

Science, BK21 Four, Mokpo National University, 1666 Yeongsan-ro, Cheonggye-myeon, Muan-gun,

Jeollanam-do, 58554

Email : skkim@mokpo.ac.kr 
approaches (Johnston et al., 2017). Blended simulation easily engages students with activities, leading to a better understanding of educational contents. Previous "one size fits all" education strategies cannot ensure optimized learning satisfactions; thus, further efforts are necessary for faculties to integrate new teaching methods.

Blended simulation uses multiple modalities, which benefit health professional education (Benedict et al., 2017; Coggins et al., 2017). As students progress through their school curriculum, their skill evolves in stages and blended simulation can reconstruct these modalities according to students' progress. This comprise an essential element of learner-centered education which could result in beneficial effects in acquisition of theoretical knowledge and nursing skills (Ellis DM., 2016); therefore, rigorous efforts are necessary to seek diverse educational modalities, which lead to effective blended simulation in nursing curriculum.

Blended learning accommodates individualized learning opportunities in nursing education. Previous review identified the beneficial effect of blended learning in nursing education; improving clinical skill, acquisition of theoretical knowledge and clinical confidence, and the greater level of user satisfaction (McCutcheon et al., 2015). Yet, only few previous studies adopted blended simulation on physical assessment. The purpose of this study was to examine the effects of blended simulation on undergraduate nursing education.

\section{METHODS}

\section{Blended Simulation for Respiratory System Assessment}

Two simulation technologies, SPs and HFS, were involved in this study [see Table 1]. The simulation program was designed to improve respiratory system assessment skills and patient communication skills. Six-hour simulation was implemented and the program contents consisted of the following three phases: respiratory system assessment lecture (1 hour), training using trained SPs and patient simulator (3 hours), and training using patient simulator and peers who play the patient's role ( 2 hours).

Table 1: Educational contents of blended simulation for respiratory system assessment

\begin{tabular}{|c|c|c|c|}
\hline \multirow[t]{2}{*}{ Session } & \multicolumn{2}{|c|}{ Educational contents } & \multirow[t]{2}{*}{ Duration } \\
\hline & Experimental group & Control group & \\
\hline $1^{\text {st }}$ session & \multicolumn{2}{|c|}{ Examination of respiratory system including anatomy } & 1 hour \\
\hline $2^{\text {nd }}$ session & $\begin{array}{l}\text { Educational video (how to } \\
\text { assess the respiratory system) } \\
\text { Lecturer demonstration } \\
\text { Interview with trained } \\
\text { standardized patients } \\
\text { Practicing respiratory system } \\
\text { assessment skills using patient } \\
\text { simulator } \\
\text { Students practiced discerning } \\
\text { abnormal lung sounds }\end{array}$ & $\begin{array}{l}\text { Educational video (how to } \\
\text { assess the respiratory } \\
\text { system) } \\
\text { Lecturer demonstration } \\
\text { Practicing respiratory system } \\
\text { assessment skills with peer } \\
\text { role play } \\
\text { Audio recorded sound was } \\
\text { provided for students to } \\
\text { practice discerning abnormal } \\
\text { lung sounds }\end{array}$ & 2 hours \\
\hline $3^{\text {rd }}$ session & $\begin{array}{l}\text { Practicing respiratory system } \\
\text { assessment skills on patients } \\
\text { simulator. } \\
\text { Scenario-based training with } \\
\text { peer role play }\end{array}$ & Open lab for self-practice & 2 hours \\
\hline
\end{tabular}




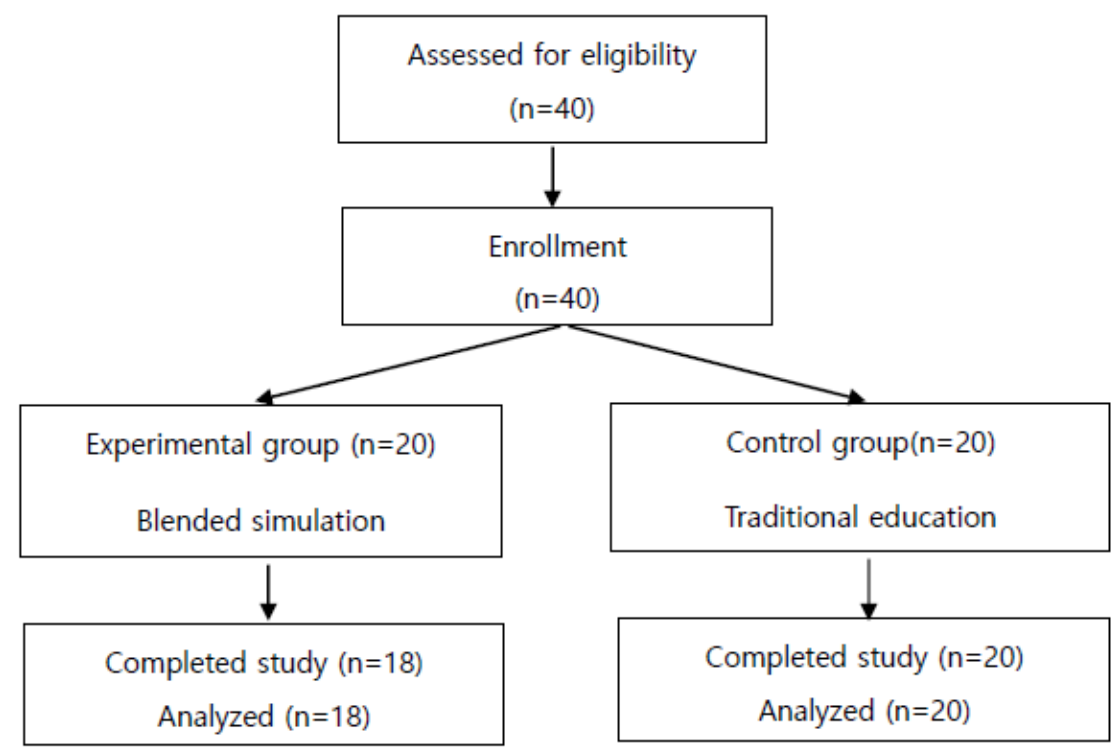

Figure 1: Study flow diagram

\section{Participants}

Forty nursing students in their second year enrolled and participated in blended simulation education. Twenty students were allocated to either the experimental or control group. Two experimental group students did not complete the post-test, thus, data from 18 students were used for statistical analysis [see Figure 1].

\section{Instruments}

\section{Health assessment skill}

Health assessment skills for the respiratory system were evaluated using CPX (Clinical Performance Examination). CPX is a tool to evaluate students' clinical reasoning ability, incorporating assessment and developing a care and treatment plan (Choi et al., 2008).

\section{Communication skill}

Communication skills were assessed using a 6-item self-reporting questionnaire. The tool analyzes conciseness, clarity, connectivity, adequacy, reliability, and eye contact. ${ }^{1}$ With a maximum score of 30 , a higher score indicates a greater ability to communicate.

Learning satisfaction was assessed after revising the existing tool for analyzing education satisfaction, developed by Lee (1999). The tool consists of 5 subscales: learner attitude (1 item), learner satisfaction (3 items), suitability of educational contents (4 items), learning achievement (5 items), and adequacy of evaluation (6 items), a total of 20 items. A 5-point Likert scale was used. The average score ranged between 1-5, with the higher score indicating a greater learning satisfaction.

\section{Data collection}

Students in each croup completed CPX and the survey one day after the simulation program finished. Students' performance during the CPX assessment was video recorded and scored by two independent raters who were blinded. The independent reviewer's scores calculated the average.

\section{Statistical Analysis}

Using SPSS (version 24), statistical analysis was conducted. Demographic data, frequent, mean, standard deviation, and percentage were calculated. The homogeneity test between groups was performed using chisquire test and independent t-test. Fisher's exact test and Mann-Whitney U test were used to compare the experimental and control group.

\section{RESULT}

The mean age of study participants were 20.22 and 20.54 , respectably. The academic scores of previous semesters were 3.35 points in blended simulation group and 3.42 points in control group. Students in the

\footnotetext{
1 Seong KY. 2008. Effects of practice nursing education: using standardized patients on subcutaneous insulin injection. Unpublished master's thesis. Eulji University: Daejeon.
} 
experimental group (72.2\%) and those in the control group (95.0\%) reported satisfaction with nursing and the majority of students $(94.5 \%$ in the experimental group and $90.0 \%$ in the control group) had fair-to-good abilities of self-expression. There was no statistically significant group difference in satisfaction with nursing $(\chi 2=3.37$, $\mathrm{p}=.167)$, self-expression $(\chi 2=1.45, \mathrm{p}=.402)$, age $(\mathrm{t}=-1.49, \mathrm{p}=.146)$, and previous semester scores $(\mathrm{t}=-.48$, $\mathrm{p}=.519$ ) [see Table 2].

Table 2. Homogeneity for characteristics between groups $(\mathbf{N}=38)$

\begin{tabular}{|c|c|c|c|c|}
\hline \multirow[b]{2}{*}{ Characteristics } & $\begin{array}{c}\text { xperimental group } \\
(\mathrm{n}=18)\end{array}$ & $\begin{array}{l}\text { Control group } \\
(\mathrm{n}=20)\end{array}$ & \multirow[b]{2}{*}{$\chi^{2} / t$} & \multirow[b]{2}{*}{$\mathrm{p}$} \\
\hline & $\begin{array}{l}\mathrm{n}(\%) / \\
\mathrm{M}(\mathrm{SD})\end{array}$ & $\begin{array}{l}\mathrm{n}(\%) / \\
\mathrm{M}(\mathrm{SD})\end{array}$ & & \\
\hline Satisfaction with nursing & \multirow[b]{2}{*}{$\begin{array}{c}13(72.2) \\
5(27.8) \\
0(0.0)\end{array}$} & \multirow[b]{2}{*}{$\begin{array}{c}13(65.0) \\
6(30.0) \\
1(5.0)\end{array}$} & \multirow[b]{2}{*}{$3.37 *$} & \multirow[b]{2}{*}{.167} \\
\hline $\begin{array}{l}\text { Good } \\
\text { Fair } \\
\text { Poor }\end{array}$ & & & & \\
\hline Self-expression & \multirow[b]{2}{*}{$\begin{array}{c}7(38.9) \\
10(55.6) \\
1(5.5)\end{array}$} & \multirow[b]{2}{*}{$\begin{array}{l}6(30.0) \\
12(60.0) \\
2(10.0) \\
\end{array}$} & \multirow[b]{2}{*}{$1.45^{*}$} & \multirow[b]{2}{*}{.402} \\
\hline $\begin{array}{c}\text { Good } \\
\text { Fair } \\
\text { Poor }\end{array}$ & & & & \\
\hline Age (yr) & $20.22(1.59)$ & 20.54(1.78) & -1.49 & .146 \\
\hline Score of previous semester (point) & $3.35(1.96)$ & $3.42(2.01)$ & -0.48 & .519 \\
\hline
\end{tabular}

After completing the educational program, there was statistically significant higher levels of health assessment skill $(\mathrm{p}<.001)$ and communication skill $(\mathrm{p}<.001)$. The experimental group's mean score totaled 4.22 (out of 5) and 3.89 in the control group after examining educational satisfaction. Comparing with control group, there was statistically significantly higher learning satisfaction in the blended simulation group $(\mathrm{p}=.002)$ [see Table 3].

Table 3. Comparisons of outcome variables between groups $(\mathrm{N}=38)$

\begin{tabular}{|c|c|c|c|c|}
\hline \multirow[b]{2}{*}{ Variables } & $\begin{array}{c}\text { Experimental group } \\
(\mathrm{n}=18)\end{array}$ & $\begin{array}{l}\text { Control group } \\
(\mathrm{n}=20)\end{array}$ & \multirow[t]{2}{*}{$\mathrm{t} / \mathrm{z}$} & \multirow[t]{2}{*}{$\mathrm{p}$} \\
\hline & $\mathrm{M}(\mathrm{SD})$ & $\mathrm{M}(\mathrm{SD})$ & & \\
\hline $\begin{array}{l}\text { Physical assessment skill } \\
\text { (respiratory system) }\end{array}$ & $83.44(8.02)$ & $67.87(8.90)$ & 7.06 & $<.001$ \\
\hline Communication skill & $4.12(0.43)$ & $3.09(0.47)$ & 7.43 & $<.001$ \\
\hline \multicolumn{5}{|l|}{ Learning satisfaction } \\
\hline Perceived self-attitude & $4.17(0.62)$ & $4.00(0.54)$ & 1.33 & .193 \\
\hline Learner satisfaction & $4.28(0.51)$ & $3.91(0.42)$ & 4.02 & $<.001$ \\
\hline Suitability of educational contents & $4.30(0.37)$ & $3.78(0.48)$ & 4.14 & $<.001$ \\
\hline Learning achievement & $4.27(0.31)$ & $4.11(0.35)$ & 0.54 & .591 \\
\hline Adequacy of evaluation & $4.20(0.48)$ & $4.08(0.44)$ & 0.80 & .419 \\
\hline Learning satisfaction (total) & $4.25(0.48)$ & $3.89(0.43)$ & $3.19 *$ & .002 \\
\hline
\end{tabular}

* Mann-Whitney U test

\section{DISCUSSION}

In this study, a quasi-experimental design was used to identify the effectiveness of blended simulation using contents of respiratory system assessment. In addition to lecture for knowledge acquisition, patient simulator and SPs were used to link theory and clinical practice during the simulation. Moreover, combining two methods of simulation allowed students to have a diverse experience, leading to better readiness of undergraduate students for future clinical practice.

Students in the experimental study were provided more diverse simulation activities, which ensures a greater opportunity to meet individuals' learning preferences. In previous studies, learning preferences has been identified as a predictor, promising good academic performance of undergraduate nursing students (Koch et al., 
2011). Students reported their learning preference using multiple approaches, which associated with the findings of the present study. Traditional, "one size fits all" education is no longer as effective as before; thus, these findings indicate the need for nursing education to transform into diverse educational methods.

The use of two kinds of patients in blended simulation enabled students to be more engaged in practice for communication. The flexibility of peer role play allows active participation in developing communication skills for diverse clinical situations. Considering the major restriction of SPs and cost, peer role play must also be well considered as an effective component for blended simulation (Bossee et al., 2012). In addition, peer role play methods allow better empathic approaches to patients than SP simulations, which further fosters active communication.

HFSs provide students the opportunity of real-like practice as students are given opportunities to directly observe breathing and listen to abnormal lung sounds of patients with particular lung diseases. Although the audio record delivers real patient sounds, it may not be enough to engage students in learning (Kim et al., 2016). Using patient simulators allows certain activities such as using a stethoscope to hear patients' lung sound, which fosters students' active participation in clinical simulation. Practicing the process of clinical decision-making on patient simulators, students work harder to make more sound clinical judgement (Loke et al., 2020). The findings of this study indicate patient simulators clearly play a vital role in linking theoretical knowledge to nursing skills for clinical practice.

Since students' health assessment skills closely relate to intensity of practice, students in blended simulation achieve high levels of performance with opportunities for practice. Nursing faculties must use diverse educational approaches such as blended learning, which could help identify its effectiveness. There might be different educational approaches in other health professional or other disciplines; therefore, nursing faculties must carefully consider how to blend and integrate other approaches into nursing education. We are living in the world where healthcare and medicine are changing on a daily basis (Harden et al., 2020); therefore, nursing education must also be ready for this constant transformation.

This study was not without limitations. Although we used convenience sampling, the study's sample size was relatively small due to restrictions on the number of students allowed in one class. In addition, using a selfreporting questionnaire for some variables (communication skill and learning satisfaction) means cautions are necessary when interpreting the study results.

\section{CONCLUSION}

This blended simulation using SPs and patient simulator successfully improved physical assessment and communication skills. In addition, students in blended simulation group reported statistically significantly higher level of learning satisfaction than control group. Providing opportunities to experience diverse educational methods could easily meet students' learning preferences, leading to better activity engagement. The development of blended simulation with professionally designed educational contents effectively improves undergraduate nursing students' competency.

\section{Funding Support}

The authors declare that they have no funding support for this study.

\section{CONFLICT OF INTEREST}

The authors declare that they have no conflict of interest.

\section{REFRENCES}

1. Barry Issenberg S, Mcgaghie WC, Petrusa ER., Lee Gordon D, Scalese RJ. 2005. Features and uses of high-fidelity medical simulations that lead to effective learning: A BEME systematic review. Medical Teacher, 27(1), 10-28.

2. Benedict N, Smithburger P, Donihi AC, Empey P, Kobulinsky L, Seybert A, et al. 2017. Blended simu lation progress testing for assessment of practice readiness. American Journal of Pharmaceutical Educa tion, 81(1), 14.

3. Bosse HM, Schultz JH, Nickel M, Lutz T, Möltner A, Jünger J, et al. 2012. The effect of using standar dized patients or peer role play on ratings of undergraduate communication training: a randomized cont rolled trial. Patient Education and Counseling, 87(3), 300-306.

4. Buist M, Stevens S. 2013. Patient bedside observations: What could be simpler? BMJ Qual Saf,. 22, 69 9-701.

5. Chan GJ, Parco KB, Sihombing ME, Tredwell SP, O'Rourke EJ. 2010. Improving health services to di splaced persons in Aceh, Indonesia: A balanced scorecard. Bull. World Health Organ. 88(9), 709-712.

6. Choi JY, Jang KS, Choi SH, Hong MS. 2008. Validity and reliability of a clinical performance examin ation using standardized patients. Journal of Korean Academy of Nursing, 38(1), 83-91.

7. Coggins A, Desai M, Nguyen K, Moore N. 2017. Early acquisition of non-technical skills using a blen 
ded approach to simulation-based medical education. Advances in Simulation, 2(1), 12.

8. Ellis DM. 2016. The role of nurse educators' self-perception and beliefs in the use of learner-centered t eaching in the classroom. Nurse Education in Practice, 16(1), 66-70.

9. Harden RM, Laidlaw JM, Mmed D. 2020. Essential skills for a medical teacher: An introduction to tea ching and learning in medicine. Elsevier.

10. Johnson N, List-Ivankovic J, Eboh W, Ireland J, Adams D, Mowatt E, Martindale S. 2010. Research an $\mathrm{d}$ evidence based practice: Using a blended approach to teaching and learning in undergraduate nurse $\mathrm{e}$ ducation. Nurse Educ. Pract. 10 (1), 43-47.

11. Johnston ANB, Weeks B, Shuker MA, Coyne E, Niall H, Mitchell M, Massey D. 2017. Nursing studen ts' perceptions of the objective structured clinical examination: an integrative review. Clin. Simul. Nurs . 13(3), 127-142.

12. Kim J, Park JH, Shin S. 2016. Effectiveness of simulation-based nursing education depending on fideli ty: A meta-analysis. BMC Medical Education, 16(1), 152.

13. Koch J, Salamonson Y, Rolley JX, Davidson PM. 2011. Learning preference as a predictor of academi c performance in first year accelerated graduate entry nursing students: A prospective follow-up study. Nurse Education Today, 31(6), 611-616.

14. Lee EK, Kim IS, Chae YM, Kim HS. 1999. Development and evaluation of internet-based distance lea rning system for health science. Journal of Korean Society of Medical Informatics, 5(3), 139-148.

15. Loke JCF, Lee BK, Loh S, Noor AM. 2020. High fidelity full sized human patient simulation manikins : Effects on decision making skills of nursing students. Journal of Nursing Education and Practice, 4(7) , 31-40.

16. McCutcheon K, Lohan M, Traynor M, Martin D. 2015. A systematic review evaluating the impact of o nline or blended learning vs. face-to-face learning of clinical skills in undergraduate nurse education. $\mathrm{J}$ ournal of Advanced Nursing, 71(2), 255-270.

17. Posey L, Pintz C. 2017. Transitioning a bachelor of science in nursing program to blended learning: Su ccesses, challenges \& outcomes. Nurse Education in Practice, 26, 126-133. 